\title{
DEPENDÊNCIA E MORTE DA "MÃE DE FAMÍLIA": A SOLIDARIEDADE FAMILIAR E COMUNITÁRIA NOS CUIDADOS COM A PACIENTE DE ESCLEROSE LATERAL AMIOTRÓFICA ${ }^{1}$
}

\author{
Claudia Fernandes Borges
}

\begin{abstract}
RESUMO. Este trabalho investiga de que modo famílias contemporâneas, de condição social desfavorecida, se defrontaram com a situação de ter a "mãe de família", adoecida por esclerose lateral amiotrófica (ELA) e dependente. Participaram da pesquisa familiares das pacientes freqüentadoras do Instituto de Neurologia Deolindo Couto, da UFRJ. O método utilizado foi uma entrevista psicológica e a Análise Qualitativa em Psicologia. Os resultados demonstraram: dificuldades impostas pela situação familiar e socioeconômica; a predominância das filhas como cuidadoras; a relevância das redes de parentesco e comunitária como suporte familiar. Concluiu-se que as famílias alcançaram condições para cuidar da paciente com praticidade e solidariedade.
\end{abstract}

Palavras-chave: Esclerose lateral amiotrófica; cuidadores familiares; gênero feminino.

\section{DEPENDENCE AND DEATH OF THE "MOTHER OF THE FAMILY": FAMILY AND COMMUNITY SOLIDARITY IN THE CARE OF THE AMYOTROPHIC LATERAL SCLEROSIS PATIENT}

\begin{abstract}
This work aims to investigate the way modern families, from a less favorable social condition, face the situation of having the "mother of the family", sick with amyotrophic lateral sclerosis (ALS), and dependent. The family members of the patients, who attended in the Neurology Institute Deolindo Couto of UFRJ, participated in this study. The method used was the Psychological Interview and the Quality Analysis in Psychology. The results showed: the difficulties imposed by the family situation, as well as the social and economic situation, the predominant role of the daughters as caretakers and the significance of the community and kinship net as the bearers of the family nucleus. It was concluded that the families demonstrated having reached the deliberation to take care of the patient in a practical and sensible way.
\end{abstract}

Key words: Amyotrophic lateral sclerosis; family caretakers; female gender.

\section{INTRODUÇÃO}

A esclerose lateral amiotrófica (ELA), patologia neurológica, crônica, degenerativa e letal, de etiologia desconhecida, caracteriza-se pela atrofia progressiva dos músculos do corpo, atingindo membros superiores e inferiores, fala e deglutição. (Lima, 1979). Acomete, principalmente, pessoas na faixa etária de 40 a 60 anos.

Devido à atrofia muscular, esta patologia leva à perda total da independência funcional, acarretando uma chocante situação para o indivíduo, que se vê prisioneiro no seu próprio corpo, desenvolvendo conteúdos de depressão e ansiedade. O caminho percorrido por pacientes e familiares ao longo de todo este processo é repleto de perdas sucessivas, de mortes parciais, traduzidas pelas constantes e irreversíveis atrofias musculares e perdas funcionais que a doença acarreta.

Os pacientes vão gradualmente perdendo a capacidade de se alimentar por via oral, pois vão tendo a musculatura responsável pela deglutição atrofiada, precisando recorrer à gastrostomia. Da mesma forma, os distúrbios respiratórios começam a se manifestar, geralmente na fase final da doença, devido às lesões bulbares que afetam a musculatura pulmonar. Observa-

1 Apoio CNPq.

Doutoranda do Curso de Pós -Graduação em Psicologia da Universidade Federal do Rio de Janeiro - UFRJ.

Endereço para correspondência: Estrada de Jacarepaguá, 7793, casa 026, Freguesia, Jacarepaguá, CEP 22753-045, Rio de JaneiroRJ. E-mail: cldborges@ig.com.br 
se dispnéia progressiva, que acaba sendo a causa mortis, na maioria dos casos, fazendo-se necessária a assistência respiratória (uso constante de oxigênio).

Enfrentam também uma progressiva paralisia/atrofia dos membros superiores e inferiores, que em pouco tempo impossibilita a locomoção e a realização de qualquer atividade que envolva o uso da musculatura corporal como um todo. No entanto, geralmente, observa-se a preservação das capacidades cognitivas, ou seja, os pacientes permanecem lúcidos e cognitivamente preservados ao longo de toda a progressão da doença. A casuística de comorbidade ELA - demência é muito baixa, ocorrendo raramente, sendo mais comum em pessoas em idade avançada.

Infelizmente ainda não existe a possibilidade de cura nem de estacionar a progressão da doença. Dessa forma, o tratamento oferecido consiste basicamente no atendimento neurológico, visando medidas paliativas (no caso, alívio e controle sintomático e combate as intercorrências), além da preservação das capacidades ainda existentes, através da intervenção dos técnicos em fonoaudiologia e fisioterapia.

Diante desta realidade, pacientes e familiares geralmente solicitam suporte psicológico que possa auxiliá-los no enfrentamento das dificuldades e das sucessivas e necessárias adaptações, tanto no âmbito familiar quanto no pessoal, por um período difícil de determinar, mas que será com certeza um tempo marcado por muito sofrimento e angústia, mas também por muitas oportunidades de amadurecimento.

Destarte, o atendimento adequado a pacientes portadores de uma enfermidade como a esclerose lateral amiotrófica (ELA) requer uma abordagem que necessariamente inclua a família, os serviços de saúde e a comunidade do paciente, esta última, justificandose, principalmente em se tratando de classes sociais menos favorecidas, tendo-se em vista as múltiplas dificuldades enfrentadas por essas famílias na conjugação doença incapacitante/situação socioeconômica desfavorável. Viabilizar as melhores condições possíveis de atendimento a esses pacientes e familiares requer a criação de formas conjuntas de atuação entre família, comunidade e serviço de saúde.

Além disso, considerando-se as estatísticas que apontam para o aumento da expectativa de vida (longevidade), a incidência de doenças crônicas e degenerativas tende a aumentar. Esta realidade nos chama a atenção para a carência de políticas de saúde pública que atendam a esta demanda crescente e para a necessidade de se pensarem novas formas de atuação diante de doenças com prognósticos semelhantes.

\section{A FAMÍLIA E A MULHER NA ATUALIDADE}

As famílias têm passado por transformações internas muito intensas, que apontam para tentativas de criação de novas estruturas que possibilitem o enfrentamento da realidade atual, caracterizada por ideologias individualistas, relacionamentos descartáveis, valorização do material em detrimento do emocional e espiritual, e ao mesmo tempo preservem, de alguma forma, as condições que temos de estar inseridos e de participar de uma vida familiar, seja ela qual for.

Velho (1989) chama a atenção para a família atual, que aparentemente se apresenta à primeira vista como nuclear, mas na verdade está imersa numa rede de relações entre as mais diversas formas de família, num complexo sistema de interdependência, que é fundamental para sua sobrevivência e equilíbrio, embora tal rede, na maioria das vezes, possa parecer invisível. Esta rede inclui parentes, amigos e vizinhos e se revela fortemente atuante em praticamente todos os momentos da vida, mas se torna vital, principalmente, nos momentos de crise.

Bilac (1995) reforça a existência e a importância da solidariedade entre as pessoas das classes populares, e o quanto esta realidade é mais freqüente do que imaginamos. Segundo estudos feitos por Woortmann (1987), as pessoas procuram sempre se fixar próximas à rede de parentesco, justamente procurando garantir uma maior proximidade e facilidade de contato em caso de necessidade, e isso é particularmente comum nas classes populares, dado o grau de dificuldades e os poucos recursos materiais de que dispõem para conseguir autonomia na solução de seus problemas cotidianos.

Segundo Cantor (citado por Silva, 1996), apesar das mudanças que vêm ocorrendo na dinâmica familiar, esta continuará a desempenhar o importante papel de prover cuidados físicos, emocionais e sociais. No entanto, algumas das funções que antes exercia isoladamente estão sendo gradualmente divididas com a comunidade, principalmente nas classes populares, que se complementam na busca por uma resolutividade, ainda que parcial, de suas crises internas.

Ao contrário do que se constata no discurso lato sensu, a família não é natural, imutável, mas muito ao contrário, como nos mostra Durham (1983), precisamos "dissolver sua aparência de naturalidade, percebendo-a como criação humana mutável"(p.15).

As razões que levaram a mulher a ser associada "naturalmente" ao papel de cuidadora, segundo Ortner (1979), têm relação com o fato de a mulher ser considerada como mais próxima à natureza e 
consequientemente associada aos cuidados, à vida, à morte, ou seja, ao biológico, enquanto o homem é associado à cultura, às relações sociais, políticas, etc.

Destacamos aqui a origem cultural da divisão sexual de papéis para mostrarmos o mecanismo que leva à associação da mulher ao papel "natural" de cuidadora do lar, da família e dos doentes, ou seja, de cuidadora de todas as gerações, ao papel de "enfermeira natural", de "mãe de família" e, conseqüentemente, de figura central na dinâmica familiar. Dessa forma, é possível imaginar as desorganizações que ocorrem no âmbito familiar quando esta "mãe de família" adoece e se torna dependente total e, conseqüentemente, as reorganizações que são necessárias para que se encontrem soluções que dêem conta do cuidar desta paciente e da manutenção da família.

Mercier (citado por Silva, 1996) aponta ainda outro fator significativo: que quando filhos e filhas moram longe dos pais, são as filhas que tradicionalmente mantêm contato com o sistema familiar. São também as filhas que assumem o papel de cuidadoras, quando isso se faz necessário. Por outro lado, os filhos homens, quando moram perto dos pais, em geral somente se tornam cuidadores à revelia, isto é, quando não há uma mulher para assumir este papel. Woortmann (1987) reforça ainda que são as mulheres que normalmente procuram e cuidam dos laços de parentesco, são elas que mantêm fortes essas relações.

\section{A CRISE DO ADOECIMENTO E DA PERDA NA FAMÍLIA}

Segundo Romano (1997), é imprescindível a participação da família quando um de seus membros adoece, isto porque o adoecimento interfere no equilíbrio do sistema familiar. As mudanças, de um modo geral, são propiciadoras de crises, e em casos de adoecimento, tais crises advêm principalmente do estresse gerado pela quebra na rotina familiar, das redistribuições repentinas e forçadas dos papéis familiares, do aumento de custos, das inseguranças, das culpas, enfim, das exacerbações e atualizações de crises antigas e de sentimentos antes não manifestados.

Walsh e McGoldrick (1998) afirmam que o choque de uma perda ou do diagnóstico de doença fatal, quando atinge uma família, faz exigências urgentes - uma nova organização deve ser estabelecida e vai se refletir na identidade, na dinâmica e nos objetivos dessa família, talvez até mesmo de forma irreversível. Quando o processo de morrer é prolongado, os recursos familiares, tanto financeiros quanto de prestação de cuidados, podem se esgotar e as necessidades dos outros membros são colocadas em suspenso.

Um fator igualmente muito importante, que afeta o núcleo familiar quando um de seus membros se encontra seriamente adoecido, é o luto antecipatório, que nesse momento vem agravar o estresse sofrido pela família. A expressão "luto antecipatório", criada por Lindemann (1944), refere-se à ausência de manifestação aberta de luto na época da morte, em pessoas enlutadas, que em rigor já passaram pelas fases do luto normal e se libertaram de seus elos emocionais com a pessoa falecida.

Torres (2001) nos lembra que não apenas os sobreviventes, mas também o paciente, vivem um processo de luto antecipado, que tem início desde o momento em que ele percebe sua morte como inevitável, envolvendo angústia e dor da separação, , que se manifestam através de reações emocionais diversas - hostilidade, culpa, depressão, tristeza, ódio, etc. - as quais de alguma forma vão possibilitar o desengajamento ou dissolução dos laços. Esses lutos antecipados, do paciente e dos sobreviventes, têm um processo cujas dinâmicas estão paralelamente vinculadas entre si, segundo nos alerta Torres (2001) e que, em muitos casos, pode ser disfuncional para o paciente e para a própria família se tais elaborações não ocorrerem simultaneamente.

Walsh e McGoldrick (1998) afirmam que na fase crônica diferentes dilemas se apresentam para as famílias: com as freqüentes demandas por cuidado, a exaustão e a ambivalência se tornam comuns à medida que os recursos financeiros e emocionais se esgotam, mobilizando culpa e remorso, que raramente são verbalizados e elaborados adequadamente.

Neri (1993) aponta outro aspecto quando se fala em doenças crônicas e incapacitantes, que é a questão do estresse do cuidador principal, ou seja, aquele que permanece centralizando os cuidados com o paciente, aquele que está sempre presente, e isso se deve à influência que o estado emocional deste exerce nos cuidados e no bem-estar do paciente e na qualidade de vida de ambos.

Desta forma, a finalidade da pesquisa aqui descrita foi estudar as dificuldades e soluções encontradas pelas famílias que se defrontam com a situação de sustentar a inclusão, em sua dinâmica interna, de pessoa portadora de uma doença que irá provocar, em médio prazo, dependência total, principalmente quando é a mulher quem adoece, tendo-se em vista a centralidade de suas atividades para a família. 


\section{OBJETIVO}

Este trabalho orientou-se no sentido de investigar de que modo famílias contemporâneas de condição social menos favorecida enfrentam a situação de ter um de seus membros, especificamente a mulher "mãe de família", acometida por esclerose lateral amiotrófica e, portanto, dependente e caminhando para a morte.

\section{METODOLOGIA}

Participantes: 20 familiares de pacientes do sexo feminino portadoras de esclerose lateral amiotrófica (ELA), escolhidos aleatoriamente entre os que freqüentam o Ambulatório Especializado em Doenças do Neurônio Motor (DNM), do Instituto de Neurologia Deolindo Couto da Universidade Federal do Rio de Janeiro.

Instrumento: Foi elaborada uma entrevista semidirigida, seguindo as orientações para uma Investigação Operativa (Bleger, 1995) (Anexo 1)

\section{Procedimentos}

\section{Aplicação da Entrevista}

Os procedimentos da aplicação da entrevista iniciaram-se com um estudo piloto que pretendia verificar a adequação das questões inicialmente propostas, no sentido de alterar ou suprimir aquelas que se revelassem mal-formuladas, de difícil compreensão, ambíguas e/ou repetitivas. Após as modificações decorrentes das observações do estudo piloto, a forma final da entrevista ficou com 25 itens, divididos em 4 questões que abordam problemas relativos à caracterização do grupo familiar e outras que abordam a situação do adoecimento e as conseqüências para a família.

Da mesma forma que no estudo piloto, as entrevistas foram realizadas individualmente, com apenas um familiar de cada paciente, sem limite de tempo, e registradas através de anotações da entrevistadora.

A orientação de Bleger (1995) fundamentou a estruturação e a condução da entrevista. Segundo o autor, este é um momento que vai muito além da mera coleta de dados de uma anamnese ou de uma consulta. Nas palavras do autor: “(...) a entrevista psicológica é uma relação, com características particulares, que se estabelece entre duas ou mais pessoas" (p.12) A entrevista psicológica, segundo esse autor, se organiza como um campo onde investigador e investigado interagem. $\mathrm{O}$ investigador se orienta para uma investigação operativa: ao mesmo tempo que investiga, intervém. É o momento propício ao desenvolvimento de um trabalho psíquico sobre os afetos, o cuidado, a solidariedade, a capacidade de compartilhar o amor e o sofrimento (Bleger, 1995). Para a análise dos dados coletados, optamos pela Análise Qualitativa do Fenômeno Situado, proposta por Martins e Bicudo (1989), que se constitui das seguintes etapas:

\section{Análise Qualitativa do Fenômeno Situado}

Da totalidade do material coletado nas entrevistas, foram selecionadas as questões condizentes com os propósitos deste trabalho que se mostraram pertinentes à Análise Qualitativa do Fenômeno Situado, segundo a orientação de Martins e Bicudo (1989), forma escolhida para a análise dos dados deste estudo por entendermos que estamos em busca não dos fatos, mas dos significados destes fatos para os sujeitos.

Este modelo de análise se constitui de quatro momentos a serem seguidos:

1. Leitura para apreensão global do sentido geral das respostas: após a organização das respostas, foram feitas diversas leituras do material, tendo por objetivo a apreensão global do sentido geral das respostas, sem buscar qualquer interpretação.

2. Leitura para encontrar unidades de significados: procedeu-se à releitura dos discursos, com o objetivo de discriminar "unidades de significado", dentro de uma visão psicológica, na perspectiva do pesquisador.

3. Leitura para encontrar insights psicológicos nas unidades de significado: uma vez obtidas as unidades de significado, uma nova releitura foi feita, dessa vez buscando o significado contido nas unidades de significado. Busca-se aqui, dentro das múltiplas realidades expressas pelos sujeitos, um significado obtido através da reflexão e da criatividade do pesquisador.

4. Síntese integradora dos insights das unidades de significado: buscaram-se, então, as convergências e divergências de todas as unidades de significado, visando tematizar ou categorizar o fenômeno através da fala dos sujeitos. É justamente no cruzamento das intersubjetividades que se desvelam significados comuns, permitindo assim a compreensão da estrutura e da essência do que foi obtido, sintetizando todas as unidades de significado, transformadas em uma proposição referente às experiências dos sujeitos, e transformando-as em uma descrição consistente da estrutura do fenômeno. 


\section{RESULTADOS}

\section{Caracterização do grupo familiar}

A idade dos familiares-informantes variou entre 14 e 64 anos, observando-se uma predominância no intervalo de 40-50 anos, com um total de seis familiares (30\%). Já com relação às pacientes, a idade variou entre 37 e 77 anos. No item grau de parentesco, a predominância foi das filhas, perfazendo um total de 12 pessoas $(60 \%)$. O item profissão dos familiaresinformantes variou imensamente, e no que se refere às pacientes predominou a categoria "do lar", com um total de 13 pessoas (65\%). O estado civil predominante foi o de casado, tanto para os familiaresinformantes (50\%) quanto para as pacientes (70\%). A função de cuidador $^{2}$ foi exercida predominantemente pelas filhas das pacientes $(65 \%)$, da mesma forma que a de responsável ${ }^{3}$ (65\%). Na função de cuidadorresponsável ${ }^{4}$, também há um maior número de filhas (55\%). Vale ressaltar que em $35 \%$ dos casos essa função (cuidador-responsável) não foi ocupada, ou seja, nestes casos há um cuidador e um responsável diferentes.

A Análise Qualitativa do Fenômeno Situado, proposta por Martins \& Bicudo (1989), possibilitou a apreensão do sentido global da fala dos entrevistados, após diversas leituras, sentido que pode ser sintetizado na frase abaixo:

\begin{abstract}
A grande dificuldade sentida pela dependência da mulher que adoeceu desorganiza o cotidiano familiar, levando os seus membros a buscar ajuda para compartilhar os cuidados com a paciente e as tarefas domésticas num percurso de luto antecipatório pela perda dessa mulher.
\end{abstract}

A releitura dos discursos, com o objetivo de discriminar "Unidades de Significado", permitiu que encontrássemos os cinco itens abaixo:

2 Cuidador é aquele que exerce os cuidados básicos com a paciente ( higiene, alimentação, vestuário, administração de medicamentos).

3 Responsável é aquele que administra em assuntos de dinheiro, compra de remédios, exames, transporte, decisões; é quem representa a família no Hospital.

4 Cuidador-responsável é quem exerce concomitantemente as duas funções: cuida e administra, responsabilizando-se pelas decisões necessárias, mesmo que exista ainda uma outra pessoa que exerça a função também e somente de cuidador. a) o impedimento da mulher, pela doença, é fator fundamental para a desorganização do cotidiano familiar;

b) o modelo atual de família apresenta grande dificuldade em resolver a situação gerada pela doença da mulher (mãe, dona-de-casa, provedora, etc.);

c) agregação e ações compartilhadas no núcleo familiar são os recursos possíveis para a resolução da situação;

d) existe a necessidade da rede comunitária como suporte para o núcleo familiar;

e) o luto antecipatório sofrido pela família se traduz num processo de desligamento afetivo gradual que ocorre na relação com a paciente.

Uma vez obtidas as unidades de significado, uma nova releitura foi feita, dessa vez buscando os significados contidos nas unidades de significado, que foram os seguintes:

a) a mulher, "mãe de família", é o sujeito de operações do cotidiano familiar (é ela quem realiza, quem faz e administra a dinâmica familiar);

b) o modelo atual de família, regido pelo individualismo, se apresenta também nas classes sociais menos favorecidas, embora atenuado e com características próprias desta realidade;

c) o núcleo familiar é a origem da construção da solidariedade;

d) da intimidade solidária do núcleo familiar se expande a construção da rede solidária de parentesco e comunitária;

c) a inter-relação familiar que se estabelece na condição de dependência e terminalidade já contém aspectos que denotam o processo de luto antecipatório.

Partiu-se, então, em busca das convergências e divergências de todas as unidades de significado, visando tematizar ou categorizar o fenômeno através das falas dos sujeitos.

Como afirmado anteriormente, é justamente no cruzamento das intersubjetividades que se desvelam significados comuns, o que permitindo a compreensão da estrutura e da essência do que foi obtido, sintetizando todas as unidades de significado transformadas em uma proposição consistente referente às experiências dos sujeitos:

A mulher que adoece e se torna dependente desloca-se do lugar de sujeito das operações do cotidiano familiar (aquela que cuida de tudo e de todos, que administra e organiza a 
dinâmica familiar) para um lugar de objeto de cuidados. O fato de não mais poder exercer tais atividades provoca uma remodelação da estrutura individualista dessa família, através da mobilização solidária dos seus membros e do entorno - parentes e a comunidade - para cuidar dela e da casa. $\mathrm{O}$ adoecimento provoca um deslocamento da mulher desse papel, cujo lugar, ficando vazio, geralmente é ocupado por outra(s) mulher(es) da família, freqüentemente a(s) filha(s). A longa convivência nesta situação de grande dificuldade, no confronto com a incapacidade e a aproximação da morte, gera um processo de luto antecipatório nos familiares e na paciente, podendo causar conflitos se não ocorrerem em sintonia, tendo em vista que um deles, pacientes ou familiares, pode estar elaborando, enquanto o outro pode ainda não ter entrado nesse processo. No entanto, a elaboração progressiva desse luto provê crescimento humanitário para todos.

\section{DISCUSSÃO}

O sentido global apreendido nas falas dos participantes aponta para a intensa dificuldade sentida pela dependência total da mulher que adoeceu, desorganizando o cotidiano familiar e levando seus membros a buscar ajuda para compartilhar os cuidados com a paciente e as tarefas domésticas, em um percurso de luto antecipatório pela perda dessa mulher.

Observamos que o impedimento da mulher, pela doença, é fator fundamental da desorganização do cotidiano familiar, devido à centralidade de suas funções. Além disso, não podemos deixar de apontar aspectos que caracterizam especificamente essas famílias estudadas, como, por exemplo, as condições socioeconômicas, o que lhes confere algumas características. Os pacientes portadores de ELA, pacientes crônicos e dependentes totais, não possuem outro "lugar" senão a família, para deles cuidar. Não há outra instituição, no momento, que dê conta desse cuidar, que pode se estender lentamente por muitos anos.

Constatamos que é na extensão da rede social que se encontra freqüentemente o auxílio daqueles que não pertencem ao grupo familiar, mas que se importam realmente e, estando próximos, criam relações de interdependência, na tentativa de suprir as faltas e de preencher os vazios deixados pelas instituições oficiais. Constatamos, ainda assim, uma sobrecarga para a "cuidadora principal", haja vista o relato de insuficiência de medidas que lhe permitissem um descanso do intenso desgaste físico e emocional, em função de seu envolvimento com questões relacionadas ao adoecimento, à dependência $\mathrm{e}$ à morte.

Por outro lado, nos momentos de maior crise, de radicalidade, as famílias carentes conseguiram vencer os obstáculos e disponibilizar os recursos possíveis, e os papéis familiares se rearrumaram de forma a tentar enfrentar a situação, mostrando, em última instância, o perfil flexível que as caracteriza, emergindo então, a solidariedade entre os membros de uma mesma família e entre as famílias de uma comunidade.

Nem sempre esses laços afetivos e de solidariedade surgem espontaneamente: muitas vezes, necessitam ser resgatados, trabalhados e revitalizados pela intervenção psicológica, no sentido de pôr em questão conteúdos de afeto e compromisso, ajuda e cuidado, solidariedade, dependência e interdependência, direitos e deveres. Muitas vezes não é possível criar hoje o que não foi gestado no passado, cabendo ao profissional perceber quando é produtivo ou não insistir na construção de uma relação de compromisso. Nestes casos torna-se necessário fazer uma busca junto a outros membros da família e/ou comunidade à procura de laços de cuidado.

Observamos que as filhas são as cuidadoras principais, confirmando as colocações de Mercier (citado por Silva, 1996) e Cantor (citado por Silva, 1996) e, na falta delas, uma outra mulher da família exercia essa função. É interessante observar ainda que apesar de $70 \%$ das pacientes serem casadas, isto não garantiu que fossem cuidadas pelos maridos. Acreditamos que esses casos de pacientes casadas cujos maridos não apareceram nem como cuidadores nem como responsáveis, podem ser entendidos por duas vertentes: ou isso é devido ao fato de o marido trabalhar para prover a família ou porque os homens não se vêem como cuidadores - isto em função de diversos fatores: culturais, sociais, ideológicos - e acabam delegando essas funções para as mulheres da família, preferencialmente as filhas.

Nos casos em que os maridos cuidam, observamos que o fazem por não haver uma mulher próxima e disponível para ocupar esse lugar, o que corrobora os achados de Mercier (citado por Silva, 1996) sobre os homens serem cuidadores somente à revelia, ou seja, quando não há alternativa.

As dificuldades surgidas devido à doença aproximaram esses familiares através da rede de parentesco (Woortmann, 1987; Jelin, 1995) e da rede comunitária ou "rede social significativa" (Sluzki, 1997) que, unidas, promoveram o suporte necessário ao núcleo familiar para enfrentar as dificuldades, 
tornadas mais complexas à medida que a doença progredia. Esta rede de apoio atua fornecendo as condições mínimas necessárias para que se promova a ação, que se transforme uma situação, tendo em vista que, na maioria das vezes, é apenas com essa rede que as pacientes podem realmente contar, não acontecendo o mesmo com a rede de hospitais, de instituições públicasem geral, que têm deixado de cumprir as funções básicas a que se propõem (atendimento clínico, suporte psicológico, etc.).

No entanto, vale ressaltar que não é objetivo da rede oficial (como os hospitais, por exemplo) atender sozinha a todas as demandas das famílias, principalmente em situações como a de pacientes portadores de esclerose lateral amiotrófica, doença crônica que se estende por um longo período, em que não há necessidade de internação hospitalar, mas sim, de apoio para que os familiares possam cuidar desses pacientes e de si mesmos.

Uma rede não exclui a outra, muito pelo contrário, poderiam e deveriam sim, trabalhar juntas no sentido de promover uma maior qualidade e capacitação de uma assistência complementar, mais integrada, na qual um diálogo permanente possibilitasse a criação de projetos que pudessem atender às reais dificuldades, mas que levassem em consideração a potencialidade e resolutividade das pessoas envolvidas, as quais se mostram efetivas, conforme pudemos observar em nossa pesquisa, apesar de todos os limites impostos pela realidade.

Nos pacientes portadores de ELA temos observado que aqueles que possuem uma rede social mais participativa são os que expressam uma qualidade melhor na assistência, tanto em nível orgânico (cuidados, contatos, visitas, passeios) quanto emocional, que permitem um pouco de lazer, afetividade e atenção, fazendo muita diferença na qualidade de vida.

A importância de se falar no estresse do cuidador se deve à influência do estado físico e emocional dele - cuidador - nos cuidados e no bem-estar do paciente e na qualidade de vida de ambos. Neri (1993) afirma que a questão se torna ainda mais preocupante quando ocorre a predominância e o prolongamento temporal de estados de estresse desagradável (distresse), isto é, caracterizados por emoções negativas, principalmente se forem intensas e perturbadoras. Ou seja, os cuidadores que vivem por um longo período as perturbações físicas e emocionais, além das sobrecargas típicas de cuidar de pacientes altamente dependentes, estão expondo seus organismos a uma exigência contínua de resistência às pressões. $\mathrm{O}$ que aponta mais uma vez para a necessidade de trabalhos institucionais que incluam os familiares, que são também parte desse processo, tendo em vista que são quem de fato cuidam desses pacientes e permanecem por um longo tempo sob um forte estresse.

A Análise Qualitativa em Psicologia nos evidenciou que, o que a princípio desorganizou a família, acabou por promover uma reorganização e uma união dos seus componentes, além de agregar vizinhos e amigos, que ajudaram sem obrigações formais, porém baseados na solidariedade - valor cultivado e reforçado entre as famílias de condição socioeconômica desfavorável, superando a ideologia individualista do mundo moderno. Foi com essa rede de ajuda cotidiana e contínua que as famílias das pacientes acometidas de ELA puderam contar para encontrar soluções que permitissem suportar e enfrentar a dependência total daquela que foi o centro, o núcleo da família - a "mulher, mãe de família".

Laços afetivos estabelecidos pelas pessoas ao longo da vida, não necessariamente familiares, puderam ser muito úteis e significativos naqueles momentos, laços esses que foram construídos e que se mostraram tanto ou mais verdadeiros que muitos laços de consangüinidade. Esta pesquisa pode evidenciar que justamente quando adoece a mulher - quem historicamente sempre foi associada ao papel de cuidadora de todos e responsável pelo espaço privado - a família sofre um processo de desorganização interna, que leva a mobilização de outra mulher para ocupar esse lugar de cuidados, tendo em vista que os homens não o ocupam com a mesma maestria.

Acaba-se sempre recorrendo a elas - as mulheres - principalmente nas classes populares. Elas se encarregam do cuidar (remuneradas ou não) de várias e de todas as gerações: bebês, crianças, adultos, doentes e idosos, além de muitas vezes sustentar financeiramente a casa. São elas ainda que tudo abandonam para cuidar; no entanto, também elas adoecem e outras mulheres vêm ao encontro delas, para cuidar.

Entendemos que tornar visível o cuidado informal e, conseqüentemente, o cuidador familiar é uma tarefa de vital importância para que sejam pensadas e criadas ações preventivas em saúde pública. Tirar do anonimato os cuidadores familiares traz à tona não apenas sua imensa contribuição humanitária e solidária, mas, principalmente, suas questões e sofrimentos, de diversas ordens, que podem ser melhor compreendidos e aproveitados na busca da melhoria da qualidade nos atendimentos ao paciente e à família. 
Observando-se mais atentamente os cuidadores, o atendimento a pacientes crônicos, que hoje é um pesado desafio para o sistema de saúde e para as famílias, poderá ter a possibilidade de ser aprimorado e reestruturado com a promoção de projetos que forneçam não apenas informações, mas que abram espaço para a reflexão e para o potencial criativo e solidário destas famílias (como mostrou nossa pesquisa) formando-se redes de atuação que envolvam instituições de saúde, famílias, comunidades e pacientes.

Saber quem são os cuidadores e conhecer sua situação de perto, através de estudos mais aprofundados pode permitir também que sejam pensadas formas de minimizar os efeitos desgastantes do cuidar, visando prevenir problemas de saúde física e emocional, e, conseqüentemente, melhorar a qualidade de vida de ambos - pacientes e cuidadores.

Finalmente o que mais nos instigou e surpreendeu ao longo dessa investigação foi a constatação de que, apesar das dificuldades que se apresentam pelo adoecimento e pela realidade de vida dessas famílias, elas conseguiram, com seus recursos, cuidar dessa mulher doente de uma enfermidade radical. Tal radicalidade marca de forma definitiva os sujeitos que, de alguma forma, participam desse caminhar pacientes, familiares, comunidade e profissionais, pessoas que têm suas vidas modificadas e marcadas para sempre pelo intenso sofrimento que presenciaram.

\section{ANEXO : PROTOCOLO DA ENTREVISTA}

Entrevista $\mathrm{n}^{\mathrm{o}}$

Data:

1) Dados da paciente
a) Nome:
b) Idade:
c) Est. civil:
d) Profissão:
e) Endereço:

2) Dados do familiar
a) Nome:
b) Idade:
c) Est. civil:
d) Profissão:
e) Endereço:
f) Grau de parentesco:
g) Reside com a paciente?
h) É cuidador, responsável ou ambos?

3) Descrição do grupo familiar
a) Com quem a paciente mora?
b) Composição / papéis familiares:
c) Como é o relacionamento entre os membros da família?

4) Questões relacionadas à doença:

a) O que você sabe a respeito da ELA? Quando e como começou a doença? A que você atribui a doença da Sra........?

b) Quem cuida da paciente? Você recebe ajuda de alguém mais da família?

c) Doenças, acidentes e mortes que ocorreram na vida da paciente e de seus familiares, principalmente aquelas que ocorreram próximo à data da instalação da doença (ou seja, próximo ao início dos primeiros sintomas).

d) Reações dos membros da família (e a sua) perante a situação da doença da Sra...?

e) O que está sendo mais difícil para você nessa situação (doença)?

f) Como você está lidando com essas dificuldades?

g) Está sendo possível criar uma organização da vida familiar com a Sra......doente? Vocês receberam ajuda de pessoas da comunidade? (vizinhos, amigos etc)

h) $\mathrm{O}$ que você gostaria que houvesse aqui no INDC, no sentido de ajudá-lo a lidar melhor com essa situação?

\section{REFERÊNCIAS}

Bilac, E.D.(1995). Sobre as transformações nas estruturas familiares no Brasil: notas muito preliminares. Em Ribeiro, A. C. T. \& Ribeiro, I. (Orgs.), Família em processos contemporâneos: inovações culturais na sociedade brasileira. (pp.43-65). São Paulo: Edições Loyola.

Bleger, J.(1995). Temas de psicologia: entrevista e grupos. (Moraes, R., Trad.). São Paulo: Martins Fontes.(Trabalho original publicado em 1979)

Durham, E.(1983). Família e reprodução humana. Em Durham, E. (Org.), Perspectivas antropológicas da mulher (Vol.3). Rio de Janeiro: Zahar.

Jelin, E.(1995). Familia y género: notas para el debate. Em Estudos Feministas, 3, (2), 394-413.

Lima, J. M.B. de. (1979). Contribuição para o estudo da esclerose lateral amiotrófica: aspectos clínicos, epidemiológicos e virológicos. Dissertação de Mestrado, Universidade Federal do Rio de Janeiro, Rio de Janeiro.

Lindemann, E.(1944). Symptomatology and management of acute grief. Em: Lindemann, E. Psychiatric factors in the treatment of ulcerative colitis (pp.141-148). Boston . 
Martins, J \& Bicudo, M.A.V. (1989). A Pesquisa qualitativa em psicologia: fundamentos e recursos básicos. São Paulo: Moraes / EDUC.

Neri, A.L. (1993) (Org.). Qualidade de vida e idade madura. (Coleção Viva Idade). São Paulo: Papirus.

Ortner, S. B. (1979). Está a Mulher para o Homem assim como a natureza para a cultura? Em Rosaldo, M. Z. \& Lamphere, L. (Coord.). A mulher, A cultura e a sociedade (Coleção o Mundo, Vol. 31) . (Ankier, C. \& Gorenstein, R., Trad.). (pp.95-121). Rio de Janeiro: Paz e Terra. (Trabalho original publicado em 1978).

Romano, B.W. (1997, setembro/outubro). A família e o adoecer durante a hospitalização. Sociedade Cardiologia. Estado de São Paulo, 7, (5 SuplementoA)

Silva, E. B.N.(1996). A Relação familiar e o idoso. Gerontologia, 4 (2), 75-78.

Sluzki, C. E. (1997). A rede social: Proposições gerais. Em Sluzki, C. E. A rede social na prática sistêmica. (pp.37-66). Rio de Janeiro: Casa do Psicólogo.

Torres, W. da C. (2001). As perdas do paciente terminal: o luto antecipado. Psicologia Argumento, 19(28), pp.7-12.

Velho, G.(1989) . Família e subjetividade. Em Subjetividade e solidariedade: uma experiência de geração. Rio de Janeiro: Jorge Zahar Editor.

Walsh, F. \& McGoldrick, M. (1998). Morte na família: sobrevivendo às perdas. (Dornelles, C. O., Trad.). Porto Alegre: Artmed.

Woortmann, K. (1987). A família das mulheres. (Coleção Biblioteca Tempo Universitário, n. 82). Rio de Janeiro/Brasília: Tempo Brasileiro/CNPq.

Recebido em 13/08/2002

Revisado em 05/02/2003

Aceito em 30/06/2003

O arquivo disponível sofreu correções conforme ERRATA publicada no Volume 8 Número 2 da revista. 